\title{
Changes in Self-Efficacy and Social Support after an Intervention to Increase Physical Activity Among Adults with Type 2 Diabetes in Oman
}

\section{A 12-month follow-up of the MOVEdiabetes trial}

"Thamra S. Al-Ghafri, ${ }^{1}$ Saud Al-Harthi, ${ }^{2}$ Yahya Al-Farsi, ${ }^{3}$ Angela M. Craigie, ${ }^{4}$ Elaine Bannerman, ${ }^{5}$ Annie S. Anderson ${ }^{4}$

$$
\begin{aligned}
& \text { التغييرات في الكفاءة الذاتية والدعم الاجتماعي بعد تدخل لزيادة النشاط البدني } \\
& \text { بين البالغين المصابين بداء السكري من النوع الثاني في عُمان } \\
& \text { MOVEdiabetes متابعة لمدة } 12 \text { شهرًا لتجربية اعلئ }
\end{aligned}
$$

$$
\text { ثمرة سعيد الغافرية، سعود الحارثي، يحيى الفارسي، أنجيلا كريجي، إيلين بـانرمان، آني أندرسون }
$$

ABSTRACT: Objectives: This study aimed to describe changes in self-efficacy (SE) and social support (SS) 12 months after the MOVEdiabetes trial, an intervention designed to increase physical activity (PA) among adults with type 2 diabetes mellitus in Oman. Methods: The original MOVEdiabetes trial was conducted between April 2016 and June 2017 in Muscat, Oman. The intervention group (IG) received personalised PA consultations, pedometers and monthly messages using a web-based application, while the comparison group received usual care. Self-reported SE and SS from family and friends were assessed using validated psychosocial scales. Results: Of the 232 original participants in the trial, a total of 174 completed the 12 months follow-up study period (response rate: $75 \%$ ). However, based on intention-to-treat analysis with several imputation procedures for missing data at 3 and/or 12 months, there was a significant increase in SE scores in the IG $(+10.3,95 \%$ confidence interval [CI]: 7.1-13.5; $P<0.001)$; however, the correlation with PA levels was weak $(+4.2,95 \% \mathrm{CI}$ : $2.7-5.7 ; P<0.001)$. Higher SE scores were noted in those without comorbidities $(+12.2$, 95\% CI: 6.8-17.6; $P<0.001)$ and with high income levels $(+9.7,95 \%$ CI: $5.2-14.2 ; P<0.001)$. Additionally, SS scores increased significantly among those in the IG who received support from friends $(+2.3,95 \%$ CI: $1.1-3.7 ; P<0.001)$, but not family $(+1.2,95 \%$ CI: $-0.4-2.8 ; P=0.110)$. The reliability of the scales was acceptable for SE and SS from family, but poor for SS from friends (Cronbach's alpha coefficients $=0.82,0.82$ and 0.40, respectively). Conclusion: The PA intervention was associated with positive changes in SE and SS from friends. However, further tools for assessing psychosocial influences on PA are needed in Arab countries.

Keywords: Physical Activity; Type 2 Diabetes Mellitus; Self-Management; Health Behaviors; Social Support, SelfEfficacy; Primary Healthcare; Oman.

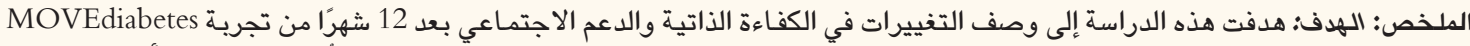

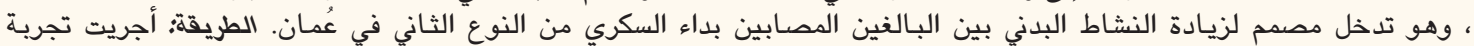

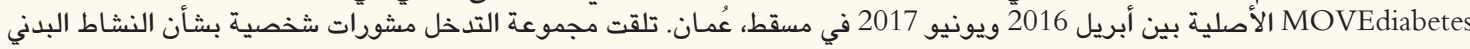

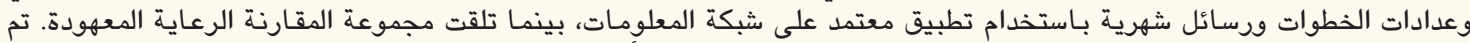

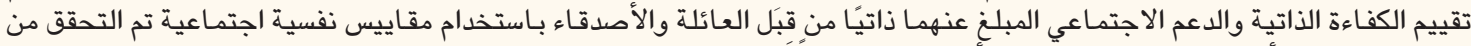

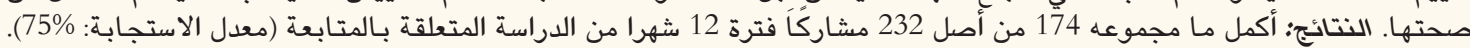

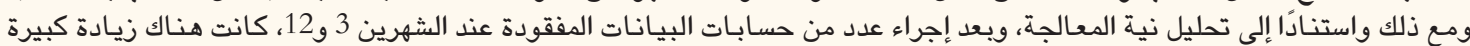

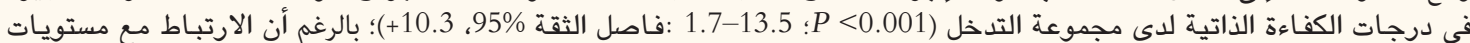

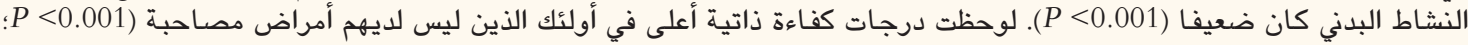

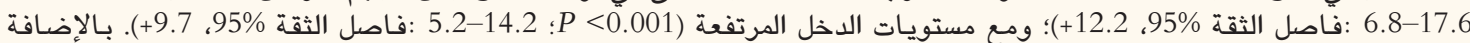

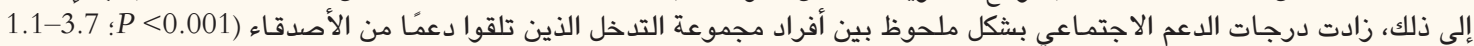

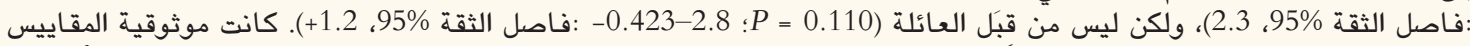

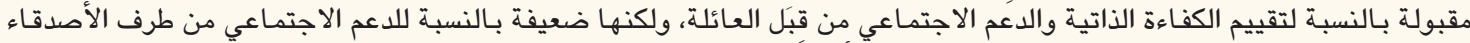

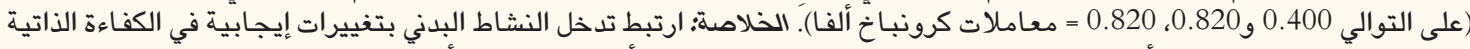

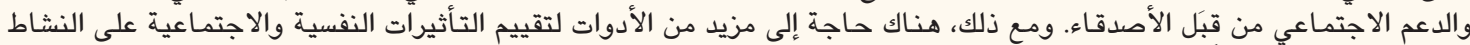
البدني في البلدان التعربيةً.

الكلمات المفتاحية: نشاط بدني؛ داء السكري من النوع الثاني؛ إدارة ذاتية؛ سلوكيات صحية؛ دعم اجتماعي؛ كفاءة ذاتية؛ رعاية صحية أولية؛ عُمان. 


\section{Advances in KNOWLEDGE}

This study's findings help address the existing gap in the literature regarding behavioural interventions to promote physical activity (PA) in Arab settings.

The study found that the MOVEdiabetes intervention to increase PA levels among adults with type 2 diabetes mellitus in Oman resulted in significant positive changes in self-efficacy and social support from friends.

\section{Application to Patient Care}

This study provides evidence to support the applicability of behavioural interventions tailored to individual needs within local clinical settings. As such, the integration of behavioural counselling techniques in primary healthcare is recommended.

$\mathrm{P}$ HYSICAL ACTIVITY (PA) HAS BEEN RECOGNISED as a cornerstone in the management of type 2 diabetes mellitus (T2DM); however, many individuals with T2DM fail to achieve the recommended target of at least 150 minutes/week of moderate to vigorous exercise. ${ }^{1}$ In Muscat, Oman, a cluster randomised controlled trial known as the MOVEdiabetes trial was conducted over one year between 2016 and 2017.2 A structured intervention was designed to increase PA levels among adults with T2DM in Oman incorporating face-to-face personalised PA consultations, pedometers and monthly messages using a webbased application. ${ }^{2}$

The MOVEdiabetes intervention was structured according to three complementary theoretical models, including the stages of change model, health belief model and social cognitive theory., ${ }^{3,4}$ In addition, behaviour change techniques (BCTs) were incorporated to facilitate the translation and application of the theories into practice; in particular, these techniques were drawn from Tudor-Locke and Lute's explanation of the effectiveness of pedometers and constructs of the theoretical models included within the Coventry, Aberdeen and London-Refined taxonomy.5,6 The final BCTs in the trial (i.e. goal setting, action planning, self-monitoring of behaviour, barrier identification, instructions on how to perform a behaviour, use of follow-up prompts and social support [SS]) have been previously identified as effective approaches to increases in PA. ${ }^{7-10}$ Specifically, self-efficacy (SE) and lack of social support (SS), particularly for females, have been identified as important barriers to the performance of PA. ${ }^{11-17}$

Therefore, the objective of the present study was to present additional follow-up findings from the MOVEdiabetes trial. ${ }^{2}$ This study sought to examine changes in factors influencing PA levels 12 months after the original MOVEdiabetes trial with regards to: (1) associations between changes in PA levels with SE and SS; (2) changes in SE and SS according to various sociodemographic factors (i.e. gender, age, education level, income level and employment status); and (3) the validity and internal consistency of the psychosocial measurement tools used to assess SE and SS.

\section{Methods}

The original MOVEdiabetes trial was performed between April 2016 and June 2017 in Muscat, Oman. ${ }^{2}$ A total of eight primary health centres were randomly selected to deliver either the intervention $(n=4)$ or provide usual care $(n=4){ }^{2,3}$ The primary outcome was to assess the effectiveness of a multicomponent intervention on changes in PA levels (primary outcome), as well as changes in weight, body mass index (BMI), glycated haemoglobin (HbA1c) level, blood pressure and lipid profile (secondary outcomes). ${ }^{2}$ Eligible participants included adults aged 18-60 years with T2DM and no contraindications to PA who were deemed by trained project officers (POs) to be inactive based on results from the Scottish Physical Activity Screening Questionnaire., ${ }^{23,18}$ Four POs were recruited from doctors and nurses who worked at diabetes clinics at each of the selected health centres.

Participants in the intervention group (IG) received personalised PA consultations, a pedometer (DigiWalker $^{\mathrm{TM}}$ SW-200, Yamax, Bridgnorth, Shropshire, UK) to measure weekly step counts and monthly messages using a web-based application (WhatsApp Messenger ${ }^{\circledR}$, Facebook Inc., Menlo Park, California, USA). ${ }^{2}$ The consultations lasted a maximum of 20 minutes and were delivered by trained POs on three separate occasions at 0 (baseline), 4 and 8 weeks. Participants in the IG received monthly standardised motivational messages and participated in a WhatsApp Messenger ${ }^{\circledR}$ group (Facebook Inc.) with the POs from their respective health centres to facilitate the reporting of their step counts and receive support during the intervention period. The content of the motivational messages was designed to coincide with international occasions to promote PA. ${ }^{2}$ The POs initiated and facilitated the group conversations, received feedback from the participants and monitored the group dynamics.

Amulticomponentinterview-basedquestionnaire was developed to elicit sociodemographic data (i.e. age, gender, marital status, education level and income), metabolic parameters (i.e. weight and BMI) and cardiovascular biomarkers (i.e. blood pressure, HbA1c level and lipid profile). ${ }^{2}$ Self-reported PA levels 
across work, travel and leisure domains were estimated via face-to-face interviews using the 13-item Global Physical Activity Questionnaire. ${ }^{19,20}$ Self-estimated PA levels were expressed as metabolic equivalent of task (MET), defined as the ratio of a person's working metabolic rate relative to their resting metabolic rate and equivalent to an energy consumption of $1 \mathrm{kcal} / \mathrm{kg} /$ hour. Target levels for biochemical variables in T2DM patients were defined according to the guidelines of the Ministry of Health in Oman. ${ }^{21}$

Subequently, two questionnaires were used to explore the participants' perceptions of SE and SS for PA at baseline and 12 months. The original English-language tools were translated into Arabic using the forward-backwards translation techniques recommended by the World Health Organization. ${ }^{22}$ The 12-item SE scale used in the study was based on the Exercise Self-Efficacy (ESE) scale. ${ }^{23}$ The ESE has been shown to be reliable after being translated to multiple other languages. ${ }^{24-26}$ In addition, a previous study conducted in Jordan found that the modified ESE demonstrated high validity and internal consistency for use in an Arabic-speaking population, based on factor analysis and internal consistency reliability tests. ${ }^{27}$

The main interest in the current study was to examine SE related to the ability to perform PA in the face of previously identified barriers to PA. ${ }^{17}$ As such, two questions in the ESE scale were modified to highlight these barriers, namely: "How confident are you that you can engage in physical activity when you do not have access to PA resources?" and "How confident are you to overcome lack of social support that could be an obstacle to performing PA?". Participants were asked to rate each item in the final 12-item Arabic questionnaire from 0 (no confidence) to 10 (complete confidence) according to their perceived current ability to perform 150 minutes of moderate to vigorous PA per week. The total possible score ranged from 0-120, with higher scores indicating greater self-confidence.

A modified version of a previously reported scale by Sallis and Hovell was used to assess perceived levels of SS. ${ }^{28}$ The scale involves a series of 13 questions to determine participants' perceptions of the level of SS received from family and friends. For the current study, modifications were made to counteract potentially gender-sensitive issues. ${ }^{17,29}$ These modifications were deemed necessary as females in Arab countries often face certain cultural norms and social expectations which may impact PA, especially in terms of perceived safety, security and modesty. ${ }^{30}$ Therefore, the first two questions were extended to determine whether they "asked someone to accompany me to perform PA" and whether family or friends "offered to drive me to the nearest PA facility". Additionally, the penultimate question was changed to determine whether they received "support to select appropriate PA clothing". Each item of the scale was asked twice to determine levels of support from family and friends independently. Each item was scored from 0 (no support) to 5 (maximum support). The total score ranged from $0-65$, with higher scores indicative of greater levels of support.

The psychosocial scales were piloted on 50 random adults selected from the patient appointment list at a diabetes clinic in one of the primary health centres. Due to the complexity of the terminology used in the scales, a statistician advised that sampling continue until a clear common understanding was reached; thus, the sampling continued for five days. Initial construct validity was performed using factor analysis. ${ }^{31}$ For the SE scale, factor loading-for which a desirable magnitude for item-factor relationships was $\geq 0$.3-was significant for three components, namely confidence to: (1) engage in PA (5 items); (2) follow PA instructions (4 items); and (3) make time for PA (3 items). This was used to structure the final version of the SE scale. No specific pattern was observed from the factor analysis for items in the SS scale. Both the SE and SS scales had acceptable internal consistency (Cronbach's alpha coefficients = 0.65 and 0.70 , respectively). ${ }^{32}$

The statistical methods used in the original MOVEdiabetes trial have been described elsewhere. ${ }^{2}$ In summary, frequency tables and t-tests were used to describe the study population and compare differences between the groups at baseline. For the current study, scores for the SE and SS scales were compared using descriptive statistics. Additionally, an independent samples t-test was used to compare summed scores between the groups at baseline. Generalised linear modelling (GLM) was performed to calculate inter-group differences in summed scores. Differences in scores according to selected sociodemographic characteristics were also explored using GLM. Spearman's correlation test was used to identify associations between changes in SE and SS scores with changes in reported PA levels. ${ }^{2}$ The level of statistical significance was set at $<0.050$. An intentionto-treat analysis was performed according to the last value carried forward imputation for missing data at 3 and/or 12 months and a mean imputation procedure was done where baseline data was missing. Factor analysis was carried out to identify components that would explain a minimum of $10 \%$ of the data variance. Item loadings of $>0.3$ were identified via principal components analysis with oblique rotation.

Ethical approval was obtained from the National Research and Ethical Review and Approve Committee in Oman Ministry of Health and reciprocally approved 


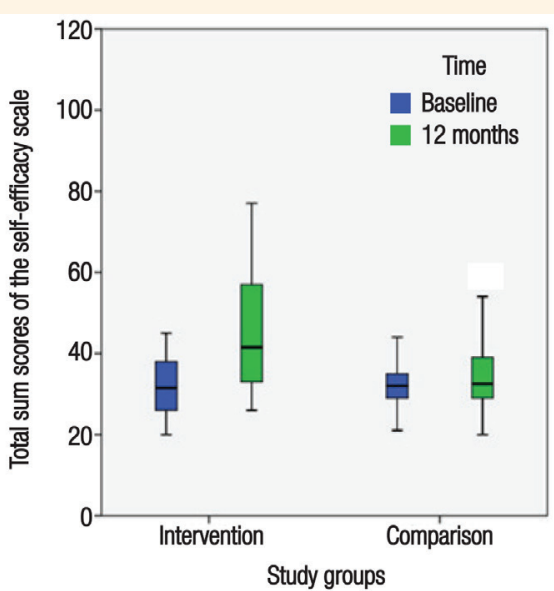

Figure 1: Box plot chart showing total sum self-efficacy* scores at baseline and 12 months later, according to group allocation among adults with type 2 diabetes mellitus in Oman $(\mathrm{N}=232)$. The intervention group $(\mathrm{n}=122)$ received personalised PA consultations, pedometers and monthly messages using a web-based application while the comparison group $(\mathrm{n}=110)$ received usual care.

"Self-assessed using a 12-item SE scale based on the Exercise SelfEfficacy scale. ${ }^{23}$ Total sum scores ranged from 0-120, with higher scores indicating greater levels of confidence.

in the University of Dundee. In addition to providing informed consent, individuals were given the right to withdraw consent for participation in any aspect of this trial at any time without affecting their routine diabetes care. All participants were advised to report any serious adverse events occurring throughout the trial as they would immediately be referred by the POs to their general practitioner. ${ }^{2}$

\section{Results}

A detailed description of the sociodemographic, anthropometric and physiological characteristics of the sample has been reported elsewhere, including a flowchart describing the participants' progress. ${ }^{2}$ Out of the 232 participants who agreed to take part in the study, a total of 227 completed baseline measurements and 174 completed the final 12-month measurements (response rates: $97.8 \%$ and 75\%, respectively). Analysis was performed utilising intent-to-treat analysis where all 232 participants were included in the analysis. ${ }^{2}$

At baseline, more than half of the participants were female $(64.5 \%$ and $54.1 \%$ in the IG and comparison group [CG], respectively). ${ }^{2}$ The mean age was $44.2 \pm 8.1$ years (median of 43 and 45 years in the IG and CG, respectively). The majority of the cohort were married (79.3\%), had completed secondary education (50.9\%) and were employed (58.2\%). ${ }^{2}$ There were significantly more married individuals in the CG than the IG $(85.5 \%$ versus $73.8 \%$; $P$ $=0.031)$. However, fewer employed individuals in the CG compared to the IG (50\% versus $65.6 \% ; P=0.022){ }^{2}$ The mean BMI was $33.8 \pm 7.9 \mathrm{~kg} / \mathrm{m}^{2}$ in the IG and $33.1 \pm 8.7 \mathrm{~kg} /$ $\mathrm{m}^{2}$ in the CG. The mean duration of T2DM was $5.8 \pm 3.7$ years, with many subjects presenting with comorbidities, including hypertension (45.3\%), hyperlipidaemia (35.6\%) or both (15\%). ${ }^{2}$

While mean systolic blood pressure (SBP) levels were within target levels in both groups, they were significantly higher in the IG compared to the CG $(83.2 \pm 9.4 \mathrm{mmHg}$ versus $78.7 \pm 14.4 \mathrm{mmHg} ; P$ $=0.003)$. Average total and low-density lipoprotein (LDL) cholesterol levels in both groups were higher than target levels. ${ }^{2}$ However, high-density lipoprotein and triglyceride levels were within target limits. Levels of HbA1c were $>7 \%$ in both groups $(71 \%$ and $58 \%$ in the IG and CG, respectively). ${ }^{2}$ There were no significant differences between groups in terms of BMI, SBP, HbA1c levels and lipid profile at baseline. At 12 months, the mean change in PA was +631.3 MET/minute/week (95\% confidence interval [CI]: 369.4-893.2 MET/minute/week) in the IG compared

Table 1: Changes in self-efficacy* at baseline and 12 months later according to group allocation ${ }^{\dagger}$ among adults with type 2 diabetes mellitus in Oman $(\mathrm{N}=232)$

\begin{tabular}{|c|c|c|c|c|c|c|c|c|}
\hline \multirow[t]{2}{*}{ Component } & \multicolumn{6}{|c|}{ Mean sum SE score s $^{\ddagger} \pm \mathrm{SD}$} & \multirow{2}{*}{$\begin{array}{c}\text { Inter-group } \\
\operatorname{MD}^{\S}(95 \% \mathrm{CI})\end{array}$} & \multirow{2}{*}{$\begin{array}{c}P \\
\text { value }\end{array}$} \\
\hline & \multicolumn{3}{|c|}{ Intervention group $(n=122)$} & \multicolumn{3}{|c|}{ Comparison group $(n=110)$} & & \\
\hline $\begin{array}{l}\text { Engagement } \\
\text { with PA }\end{array}$ & $11.8 \pm 5.0$ & $19.3 \pm 5.3$ & $7.6 \pm 6.7$ & $11.0 \pm 2.6$ & $14.4 \pm 2.9$ & $3.4 \pm 4.3$ & $+4.2(2.7-5.7)$ & $<0.001$ \\
\hline $\begin{array}{l}\text { Managing } \\
\text { time }\end{array}$ & $8.9 \pm 2.4$ & $11.6 \pm 5.5$ & $2.8 \pm 6.6$ & $9.2 \pm 2.1$ & $8.8 \pm 3.7$ & $-0.4 \pm 2.1$ & $+3.2(1.7-4.6)$ & $<0.001$ \\
\hline Total & $32.4 \pm 5.9$ & $45.7 \pm 13.8$ & $13.3 \pm 13.7$ & $31.8 \pm 4.3$ & $34.8 \pm 8.7$ & $3.0 \pm 10.9$ & $+10.3(7.1-13.5)$ & $<0.001$ \\
\hline
\end{tabular}

SE = self-efficacy; $S D=$ standard deviation; $M D=$ mean difference from baseline; $C I=$ confidence interval; $P A=$ physical activity. "Self-assessed using a 12-item SE scale based on the Exercise Self-Efficacy scale. ${ }^{23}{ }^{+}$The intervention group received personalised PA consultations, pedometers and monthly messages using a web-based application while the comparison group received usual care. ${ }^{\neq}$Total sum scores ranged from 0-120, with higher scores indicating greater levels of confidence. "Inter-group differences in sum scores were calculated using generalised linear modelling. 
Table 2: Changes in social support from family and friends* at baseline and 12 months later according to group allocation $^{\dagger}$ among adults with type 2 diabetes mellitus in Oman $(\mathrm{N}=232)$

\begin{tabular}{|c|c|c|c|c|c|c|c|c|}
\hline \multirow[t]{3}{*}{ Component } & \multicolumn{6}{|c|}{ Mean sum SS score ${ }^{\ddagger} \pm$ SD } & \multirow{3}{*}{$\begin{array}{c}\text { Inter-group } \\
\operatorname{MD}^{\S}(95 \% \mathrm{CI})\end{array}$} & \multirow{3}{*}{$\begin{array}{c}P \\
\text { value }\end{array}$} \\
\hline & \multicolumn{3}{|c|}{ Intervention group $(\mathrm{n}=122)$} & \multicolumn{3}{|c|}{ Comparison group $(n=110)$} & & \\
\hline & Baseline & 12 months & MD & Baseline & 12 months & MD & & \\
\hline Family SS & $13.5 \pm 4.5$ & $16.1 \pm 4.5$ & $+2.6 \pm 6.4$ & $10.5 \pm 3.5$ & $12.0 \pm 5.3$ & $+1.4 \pm 6.3$ & $+1.2(-0.4-2.8)$ & 0.101 \\
\hline Friends SS & $9.5 \pm 2.8$ & $12.2 \pm 5.1$ & $+2.7 \pm 6.0$ & $9.2 \pm 3.1$ & $9.6 \pm 3.0$ & $+0.4 \pm 4.2$ & $+2.3(1.1-3.7)$ & $<0.001$ \\
\hline
\end{tabular}

$S S=$ Social support SD = standard deviation; $M D=$ mean difference from baseline; $C I=$ confidence interval. "Self-assessed using a modified version of 13-item scale by Sallis et al..$^{28}$ The intervention group received personalised PA consultations, pedometers and monthly messages using a web-based application while the comparison group received usual care. ${ }^{*}$ Total sum scores ranged from 0-65, with higher scores indicating greater levels of support. IInter-group differences in sum scores were calculated using generalised linear modelling.

to +183.2 MET/minute/week (95\% CI: 83.3-283.0 $\mathrm{MET} / \mathrm{minute} /$ week in the CG, with a significant intergroup difference (+447.4 MET/minute/week; 95\% CI: 150.7-744.1 MET/minute/week; $P<0.001){ }^{2}$

Overall, total SE sum scores were found to have increased at 12 months from baseline. Summed scores for items assessing levels of confidence to engage with PA, follow PA instructions and manage time increased from $2,631 \pm 11.34$ to $3,938 \pm 16.97$, from $2,720 \pm$ 11.72 to $3,080 \pm 13.28$ and from $2,096 \pm 9.03$ to 2,387 \pm 10.29 , respectively. There was a higher contribution of questions related to engagement with PA (5 items) to overall SE score compared to other categories of items. Notably, mean total SE scores were comparable at baseline for both the IG and CG (32.4 $\pm 5.9 ; 95 \%$ CI: $31.1-33.5$ versus $31.8 \pm 4.3$; $95 \%$ CI: $31.0-32.8 ; P=$ 0.581 ) [Figure 1]. However, a univariate analysis using GLM showed a significant increase at 12 months in mean SE scores for the IG compared to the CG $(+10.3$, 95\% CI: 7.1-13.5; $P<0.001$ ) [Table 1].

Multivariate analysis indicated that participants in the IG without comorbidities had a significantly greater increase in total SE sum scores compared to IG participants with comorbidities $(+12.2,95 \% \mathrm{CI}$ : 6.8-17.6; $P<0.001)$. Similarly, individuals with higher income levels in the IG also demonstrated significantly higher total SE sum scores compared to those with lower income levels (+9.7, 95\% CI: 5.2-14.2; $P<0.001$ ). Gender was the only variable found to influence total SE sum scores in the CG, with males having a significantly greater change in sum score between baseline and 12 months compared to females $(+4.2$, 95\% CI: $0.5-7.9 ; P=0.021)$. There was a positive but weak association between changes in total SE sum scores and reported changes in PA levels within the IG only ( $\mathrm{r}=0.4 ; P<0.001)$.

Exploratory factor analysis at both baseline and 12 months indicated that all 12 items in the SE scale were suitable for the study population. According to the categorisation utilised during the piloting phase, three components were identified at baseline and 12 months: confidence to engage with PA, follow PA instructions and manage time. Inter-item correlations ranged from -0.1 to 0.9 at baseline and -0.2 to 0.8 at 12 months. The highest inter-item correlation at baseline was noted between items 2 and 4 ("How confident are you that you can engage in PA when you are in a bad mood?" and "How confident are you that you can engage in PA during bad weather?"; $r=0.9$ ). A high correlation was also identified between items 2 and 3 ("How confident are you that you can engage in PA when you are in a bad mood?" and "How confident are you that you can engage in PA when you feel you do not have time?"; $r=0.7$ ).

Similarly, at 12 months, high inter-item correlations were noted between items 6 and 7 ("How confident are you that you can follow PA directions from an instructor?" and "How confident are you that you can pace yourself during the activity to avoid overexertion?"; $r=0.8$ ) and between items 7 and 10 ("How confident are you that you can pace yourself during the activity to avoid overexertion?" and "How confident are you to arrange your schedule to perform PA regularly no matter what?"; $r=0.8$ ). At baseline and 12 months, Cronbach's alpha coefficient values for the SE scale were 0.79 and 0.82 , respectively, indicating reasonable-to-good internal consistency in this population.

Total SS sum scores were also found to have increased at 12 months from baseline from 2,804 \pm 12.1 to $3,279 \pm 14.1$ for SS from family and from 2,162 \pm 9.3 to $2,543 \pm 10.9$ for SS from friends. Overall, scores for perceived SS from family were higher than those for SS from friends in both groups. There was a difference in changes in score in the IG compared to the CG, although this difference was only significant for SS from friends $(+2.3$, 95\% CI: $1.1-3.7 ; P<0.001)$ [Table 2]. However, changes in total SS scores for either family or friends at 12 months from baseline were not significantly associated with changes in reported PA levels $(P=0.232)$.

A factor analysis of the family version of the SS scale indicated that six factors with eigenvalues of $>1.0$ significantly explained the maximum variance in data 
at baseline and 12 months. Inter-item correlations ranged from -0.1 to 0.4 at baseline and from -0.2 to 0.7 at 12 months. However, no values of $>0.7$ were identified, indicating no significant interaction between responses to the different items in the scale. Cronbach's alpha coefficient values for this subscale were 0.60 and 0.82 at baseline and 12 months, respectively, indicating good internal consistency. At 12 months, all items in the friends version of the SS scale were retained in the factor analysis, apart from items 3 and 4 ("Gave me helpful reminders to exercise" and "Gave me encouragement to stick with my exercise programme"). Seven and five factors were identified at baseline and 12 months, respectively. Inter-item correlations ranged from -0.01 to 0.5 at baseline and from -0.08 to 0.6 at 12 months. No values of $>0.70$ were identified. At baseline and 12 months, Cronbach's alpha coefficient values for the friends SS subscale were 0.20 and 0.40 , respectively, indicating poor internal consistency in this population.

\section{Discussion}

The results from the current study showed that the MOVEdiabetes intervention resulted in improvements in SE among participants of both the IG and CG groups at 12 months from baseline, with the increase being significantly greater in the IG. Similar findings have been reported in other research. ${ }^{27}$ Moreover, this increase was positively, albeit weakly, associated with changes in PA levels.

Defined as the ability to meet activity goals despite barriers, SE has been reported to be a strong predictor for performing and adhering to PA goals in various populations, including adults with T2DM.3. Despite the weak correlation between SE sum scores and perceived PA levels in the present study, it is reasonable to conclude that the results support the utilisation of this PA intervention in adults with T2DM. However, objective PA measurement would be required to validate the findings, especially in Arabicspeaking countries where PA data are limited.

In the current study, improvements in $\mathrm{SE}$ at 12 months within the IG were greater among those without comorbidities and among those who had higher incomes. The first finding may be due to such individuals being in better health, which is likely to enhance one's self-confidence and ability to perform more intense PA. ${ }^{9}$ In turn, higher income may be associated with enhanced opportunities for PA, including the ability to purchase or access additional resources, such as pedometers, watches, treadmills, gym memberships or clothing, thereby potentially facilitating positive behavioural changes. ${ }^{34}$
In addition, as in other studies, being male was associated with a greater improvement in SE in the CG. ${ }^{35}$ This suggests that gender-specific approaches may be needed to improve SE among females. ${ }^{17}$ Such approaches could offer additional support for women living in Arab countries to enable them to meet sociocultural and religious expectations related to wearing appropriate clothing and ensuring their safety while exercising in a hot climate. ${ }^{17,29,30}$

In the current study, the personalised PA consultations were designed to include specific SEenhancing techniques, namely goal setting, action planning, self-monitoring of behaviour, barrier identification, instructions on how to perform a behaviour, use of follow-up prompts and SS. ${ }^{3}$ The results showed that questions related to engagement with PA (5 items) contributed more to the overall SE score compared to other categories. Further exploration may be useful to ensure that the strategies that resulted in high PA engagement are maintained; in contrast, other less influential SE components related to following PA instructions and managing time may need to be modified or addressed to determine why they do not contribute to overall SE with regards to PA.

Several studies have highlighted the importance of SS in initiating and/or maintaining PA-related behavioural changes. ${ }^{14,36,37}$ In the current study, participants in the IG were encouraged to attend their personalised PA consultations with a family member or a friend. ${ }^{3}$ While there was a significant difference in changes in SS from friends in the IG compared to the CG, changes in family SS were not significantly different between the groups. This may not be surprising given the strong cultural importance placed on family in the Arab and Muslim world. ${ }^{38,39}$ This is reinforced by the fact that the majority of the overall study population were married, potentially indicating that the majority already received adequate levels of SS from family. ${ }^{39}$

Despite evidence of the positive effect of peer support in lifestyle modification interventions, more information is needed regarding the methods, strategies and expected outcomes when using technology to promote PA across subpopulations. ${ }^{40}$ There was no significant association between changes in reported PA levels and perceived support from either family or friends in the current study. In contrast, findings from the literature have indicated that SS has positive effects on PA levels. ${ }^{14}$ Despite using a web-based messaging application, reasons for the lack of association between PA levels and SS in the present study require further evaluation.

To the best of the authors' knowledge, the current study is one of very few to investigate the psychometric 
properties of Arabic versions of psychosocial PA scales among adults with T2DM. Based on Cronbach's alpha coefficients, the internal consistency of the scales for SE and SS from family was deemed to be acceptable, suggesting that these scales are reliable for use in Arabic-speaking T2DM patients. However, the internal consistency of the scale assessing SS from friends was weak. This could be explained by the complexity of the terminology used in the questions, especially after being translated from English to Arabic. Furthermore, the structure of the SS scale may have been confusing to the participants as they had to answer the same question twice for family and friends independently. Future research on this topic should, therefore, consider introducing the scale for family and friends separately.

This study was subject to certain limitations. Notably, the sample size was not powered to detect differences in the psychosocial scales. In addition, data were collected at baseline and 12-month followup only. Future studies may consider utilising a larger sample size and performing additional rounds of data collection on multiple occasions throughout the study period. Despite these limitations, this study's findings add valuable information to the limited literature pertaining to psychosocial scales that measure PA in Arabic-speaking populations. Further research is recommended to validate these scales in a larger cohort.

\section{Conclusion}

This study presented follow-up results regarding changes in SE and SS 12 months after the MOVEdiabetes trial, an intervention designed to increase PA levels among adults with T2DM in Oman. Although significant and positive changes were observed in SE and SS from friends within the IG compared to the CG, only SE improvements were significantly associated with changes in PA levels. In addition, measurement of the internal consistency for these psychosocial tools indicated that these scales were acceptable for use in Arabic-speaking patients with T2DM. However, further studies are needed to identify more robust tools to measure PA psychosocial influences in Arab countries.

\section{ACKNOWLEDGEMENTS}

The data generated from this study are available from the corresponding author upon reasonable request and approval from the Ministry of Health in Oman.

\section{CONFLICT OF INTEREST}

The authors declare no conflicts of interest.

\section{FUNDING}

This study was funded jointly by the Research Council and Ministry of Health in Muscat, Oman, as part of a $\mathrm{PhD}$ grant offered to the corresponding author (grant number: GRSP/MoH/15/002).

\section{References}

1. Heath GW, Parra DC, Sarmiento OL, Andersen LB, Owen N, Goenka S, et al. Evidence-based intervention in physical activity: Lessons from around the world. Lancet 2012; 380: 272-81. https://doi.org/10.1016/S0140-6736(12)60816-2.

2. Alghafri TS, Alharthi SM, Al-Farsi Y, Alrawahi AH, Bannerman E, Craigie AM, et al. 'MOVEdiabetes': A cluster randomised controlled trial to increase physical activity in adults with type 2 diabetes in primary health in Oman. BMJ Open Diabetes Res Care 2018; 6:e00605. https://doi.org/10.1136/bmjdrc-2018-000605.

3. Alghafri TS, Alharthi SM, Al-Farsi YM, Craigie AM, Mcleod M, Anderson AS. Study protocol for "MOVEdiabetes": A trial to promote physical activity for adults with type 2 diabetes in primary health care in Oman. BMC Public Health 2017; 17:28. https://doi.org/10.1186/s12889-016-3990-0.

4. Avery L, Charman SJ, Taylor L, Flynn D, Mosely K, Speight J, et al. Systematic development of a theory-informed multifaceted behavioural intervention to increase physical activity of adults with type 2 diabetes in routine primary care: Movement as medicine for type 2 diabetes. Implement Sci 2016; 11:99. https://doi.org/10.1186/s13012-016-0459-6.

5. Tudor-Locke C, Lutes L. Why do pedometers work? A reflection upon the factors related to successfully increasing physical activity. Sports Med 2009; 39:981-93. https://doi.org/10.2165/1 1319600-000000000-00000.

6. Michie S, Ashford S, Sniehotta FF, Dombrowski SU, Bishop A, French DP. A refined taxonomy of behaviour change techniques to help people change their physical activity and healthy eating behaviours: The CALO-RE taxonomy. Psychol Health 2011; 26:1479-98. https://doi.org/10.1080/08870446.2010.540664.

7. Cradock KA, ÓLaighin G, Finucane FM, Gainforth HL, Quinlan LR, Ginis KA. Behaviour change techniques targeting both diet and physical activity in type 2 diabetes: A systematic review and meta-analysis. Int J Behav Nutr Phys Act 2017; 14:18. https:// doi.org/10.1186/s12966-016-0436-0.

8. Avery L, Flynn D, van Wersch A, Sniehotta FF, Trenell MI. Changing physical activity behavior in type 2 diabetes: A systematic review and meta-analysis of behavioral interventions. Diabetes Care 2012; 35:2681-9. https://doi.org/10.2337/dc11-2452.

9. Williams SL, French DP. What are the most effective intervention techniques for changing physical activity self-efficacy and physical activity behaviour--and are they the same? Health Educ Res 2011; 26:308-22. https://doi.org/10.1093/her/cyr005.

10. Greaves CJ, Sheppard KE, Abraham C, Hardeman W, Roden M, Evans $\mathrm{PH}$, et al. Systematic review of reviews of intervention components associated with increased effectiveness in dietary and physical activity interventions. BMC Public Health 2011; 11:119. https://doi.org/10.1186/1471-2458-11-119.

11. Gleeson-Kreig JM. Self-monitoring of physical activity: Effects on self-efficacy and behavior in people with type 2 diabetes. Diabetes Educ 2006; 32:69-77. https://doi.org/10.1177/014572 1705284285

12. McAuley E. Self-efficacy and the maintenance of exercise participation in older adults. J Behav Med 1993; 16:103-13. https://doi.org/10.1007/BF00844757.

13. Oman RF, King AC. Predicting the adoption and maintenance of exercise participation using self-efficacy and previous exercise participation rates. Am J Health Promot 1998; 12:154-61. https://doi.org/10.4278/0890-1171-12.3.154. 
14. Smith GL, Banting L, Eime R, O'Sullivan G, van Uffelen JG. The association between social support and physical activity in older adults: A systematic review. Int J Behav Nutr Phys Act 2017; 14:56. https://doi.org/10.1186/s12966-017-0509-8.

15. Trost SG, Owen N, Bauman AE, Sallis JF, Brown W. Correlates of adults' participation in physical activity: Review and update. Med Sci Sports Exerc 2002; 34:1996-2001. https://doi.org/10.10 97/00005768-200212000-00020.

16. Sallis JF, Hovell MF. Determinants of exercise behavior. Exerc Sport Sci Rev 1990; 18:307-30. https://doi.org/10.1249/000 03677-199001000-00014

17. Alghafri T, Alharthi SM, Al Farsi YM, Bannerman E, Craigie AM, Anderson AS. Perceived barriers to leisure time physical activity in adults with type 2 diabetes attending primary healthcare in Oman: A cross-sectional survey. BMJ Open 2017; 7:e016946. https://doi.org/10.1136/bmjopen-2017-016946.

18. Physical Activity and Health Alliance. Scottish Physical Activity Screening Question (Scot-PASQ). From: www.paha.org.uk/ Resource/scottish-physical-activity-screening-question-scotpasq Accessed: May 2020

19. Bull FC, Maslin TS, Armstrong T. Global physical activity questionnaire (GPAQ): Nine country reliability and validity study. J Phys Act Health 2009; 6:790-804. https://doi.org/10.1123/ jpah.6.6.790

20. World Health Organization. Global Physical Activity Questionnaire (GPAQ): Analysis guide. From: www.who.int/ncds/ surveillance/steps/resources/GPAQ_Analysis_Guide.pdf Accessed: May 2020

21. Oman Ministry of Health. Diabetes mellitus management guidelines: 3rd edition 2015. From: www.moh.gov.om/docum ents / $272928 / 1314763 /$ Diabetes + Mellitus + manage ment+guidelines $+3 \mathrm{rd}+$ edition $+++2015 \% 281 \% 29 . \mathrm{pdf} /$ bafeceed-1a79-4e78-9166-9afee4ad3bf9 Accessed: May 2020.

22. World Health Organization. Management of substance abuse: Process of translation and adaptation of instruments. From: www.who.int/substance_abuse/research_tools/translation/en/ Accessed: May 2020.

23. Bandura A. Self-Efficacy: The exercise of control. New York, USA: Worth Publishers Ltd., 1997.

24. van der Heijden MM, Pouwer F, Pop VJ. Psychometric properties of the Exercise Self-Efficacy Scale in Dutch primary care patients with type 2 diabetes mellitus. Int J Behav Med 2014; 21:394-401. https://doi.org/10.1007/s12529-013-9308-z.

25. Shin Y, Jang H, Pender NJ. Psychometric evaluation of the Exercise Self-Efficacy Scale among Korean adults with chronic diseases. Res Nurs Health 2001; 24:68-76. https://doi.org/10.1002/1098$240 x(200102) 24: 1<68::$ aid-nur1008>3.0.co;2-c.

26. Noroozi A, GhofranipourF, Heydarnia AR, Nabipour I, Tahmasebi R, Tavafian SS. The Iranian version of the Exercise Self-Efficacy Scale (ESES): Factor structure, internal consistency and construct validity. Health Educ J 2010; 70:21-31. https://doi.org/10.11 $77 / 0017896910374547$

27. Darawad MW, Hamdan-Mansour AM, Khalil AA, Arabiat D, Samarkandi OA, Alhussami M. Exercise Self-Efficacy Scale: Validation of the Arabic version among Jordanians with chronic diseases. Clin Nurs Res 2016; 27:890-906. https://doi. org/10.1177/1054773816683504.
28. Sallis JF, Grossman RM, Pinski RB, Patterson TL, Nader PR. The development of scales to measure social support for diet and exercise behaviors. Prev Med 1987; 16:825-36. https://doi. org/10.1016/0091-7435(87)90022-3.

29. Alghafri TS, Alharthi SM, Al-Balushi S, Al-Farsi Y, Al-Busaidi Z, Bannerman E, et al. Health professionals' perceptions about physical activity promotion in diabetes care within primary health care settings in Oman. Heliyon 2018; 3:e00495. https:// doi.org/10.1016/j.heliyon.2017.e00495

30. Donnelly TT, Al Suwaidi J, Al Enazi NR, Idris Z, Albulushi AM, Yassin K, et al. Qatari women living with cardiovascular diseases: Challenges and opportunities to engage in healthy lifestyles. Health Care Women Int 2012; 33:1114-34. https:// doi.org/10.1080/07399332.2012.712172

31. Henson RK, Roberts JK. Use of exploratory factor analysis in published research: Common errors and some comment on improved practice. Educ Psychol Meas 2006; 66:393-416. https://doi.org/10.1177/0013164405282485.

32. Dunn TJ, Baguley T, Brunsden V. From alpha to omega: A practical solution to the pervasive problem of internal consistency estimation. Br J Psychol 2014; 105:399-412. https://doi.org/10.1111/bjop.12046.

33. Resnick B, Palmer MH, Jenkins LS, Spellbring AM. Path analysis of efficacy expectations and exercise behaviour in older adults. J Adv Nurs 2000; 31:1309-15. https://doi.org/10.1046/j.13652648.2000.01463.x

34. Kari JT, Pehkonen J, Hirvensalo M, Yang X, Hutri-Kähönen N, Raitakari OT, et al. Income and physical activity among adults: Evidence from self-reported and pedometer-based physical activity measurements. PLoS One 2015; 10:e0135651. https:// doi.org/10.1371/journal.pone.0135651.

35. Heiss V, Petosa R. Correlates of physical activity among adults with type 2 diabetes: A systematic literature review. Am J Health Educ 2014; 45:278-87. https://doi.org/10.1080/193250 37.2014 .933139

36. Rosenstock IM, Strecher VJ, Becker MH. Social learning theory and the health belief model. Health Educ Q 1988; 15:175-83. https://doi.org/10.1177/109019818801500203.

37. Gristwood J. Applying the health belief model to physical activity engagement among older adults. Illuminare 2011; 9:59-71.

38. Crescent of Care Nursing Model. Family in Arab culture. From: www. crescentofcare.com/family-in-arab-culture Accessed: May 2020.

39. Benjamin K, Donnelly TT. Barriers and facilitators influencing the physical activity of Arabic adults: A literature review. Avicenna 2013; 2013:8. https://doi.org/10.5339/avi.2013.8.

40. Ginis KA, Nigg CR, Smith AL. Peer-delivered physical activity interventions: An overlooked opportunity for physical activity promotion. Transl Behav Med 2013; 3:434-43. https://doi. org/10.1007/s13142-013-0215-2. 